\title{
Economic costs of obesity in Thailand: a retrospective cost-of-illness study
}

\author{
Paiboon Pitayatienanan ${ }^{1,2}$, Rukmanee Butchon ${ }^{2}$, Jomkwan Yothasamut ${ }^{2}$, Wichai Aekplakorn ${ }^{3}$, \\ Yot Teerawattananon ${ }^{2}$, Naeti Suksomboon ${ }^{2,4}$ and Montarat Thavorncharoensap ${ }^{1,2^{*}}$
}

\begin{abstract}
Background: Over the last decade, the prevalence of obesity $\left(\mathrm{BMI} \geq 25 \mathrm{~kg} / \mathrm{m}^{2}\right)$ in Thailand has been rising rapidly and consistently. Estimating the cost of obesity to society is an essential step in setting priorities for research and resource use and helping improve public awareness of the negative economic impacts of obesity. This prevalence-based, cost-of-illness study aims to estimate the economic costs of obesity in Thailand.
\end{abstract}

Methods: The estimated costs in this study included health care cost, cost of productivity loss due to premature mortality, and cost of productivity loss due to hospital-related absenteeism. The Obesity-Attributable Fraction (OAF) was used to estimate the extent to which the co-morbidities were attributable to obesity. The health care cost of obesity was further estimated by multiplying the number of patients in each disease category attributable to obesity by the unit cost of treatment. The cost of productivity loss was calculated using the human capital approach.

Results: The health care cost attributable to obesity was estimated at 5,584 million baht or $1.5 \%$ of national health expenditure. The cost of productivity loss attributable to obesity was estimated at 6,558 million baht - accounting for $54 \%$ of the total cost of obesity. The cost of hospital-related absenteeism was estimated at 694 million baht, while the cost of premature mortality was estimated at 5,864 million baht. The total cost of obesity was then estimated at 12,142 million baht (725.3 million US\$PPP, 16.74 baht $=1$ US\$PPP accounting for $0.13 \%$ of Thailand's Gross Domestic Product (GDP).

Conclusions: Obesity imposes a substantial economic burden on Thai society especially in term of health care costs. Large-scale comprehensive interventions focused on improving public awareness of the cost of and problems associated with obesity and promoting a healthy lifestyle should be regarded as a public health priority.

Keywords: Cost-of-illness, Obesity, Overweight, Thailand, Economic

\section{Background}

Obesity (defined as having a Body Mass Index (BMI) greater than or equal to $\left.30 \mathrm{Kilogram}(\mathrm{Kg}) / \operatorname{Meter}(\mathrm{M})^{2}\right)[1]$, is a growing health concern worldwide. It is a known risk factor for a number of chronic diseases including cardiovascular diseases, diabetes, musculoskeletal disorders, and some cancers [2-5]. Aside from increased morbidity, obesity has also been found to increase premature mortality

\footnotetext{
* Correspondence: montarat.tha@mahidol.ac.th

${ }^{1}$ Social and Administrative Pharmacy Division, Department of Pharmacy,

Faculty of Pharmacy, Mahidol University, Bangkok, Thailand

${ }^{2}$ Health Intervention and Technology Assessment Program (HITAP),

Ministry of Public Health, Nonthaburi, Thailand

Full list of author information is available at the end of the article
}

[6-8], decrease productivity due to absenteeism and presenteeism [9], and decrease quality of life [10-13].

As a result of increasing global urbanisation, changes in dietary habits, and declining levels of physical activity, the obesity epidemic is no longer limited to populations in Europe and North America [14-17]. Today, it affects populations in most countries, including those in Latin America and Asia. According to the World Health Organisation (WHO), the global prevalence of obesity has more than doubled between 1980 and 2008 [18]. In 2008, the WHO estimated that more than 1.4 billion adults aged 20 and over were overweight (a BMI greater than or equal to 25 $\left.\mathrm{Kg} / \mathrm{M}^{2}\right)$ [18]. Of these overweight adults, 500 million were obese [18].

\section{Biomed Central}

(c) 2014 Pitayatienanan et al.; licensee BioMed Central Ltd. This is an Open Access article distributed under the terms of the Creative Commons Attribution License (http://creativecommons.org/licenses/by/2.0), which permits unrestricted use, distribution, and reproduction in any medium, provided the original work is properly credited. 
The economic cost of obesity is substantial. According to one estimate from a recent systematic review, the health costs associated with obesity may account for between $0.7 \%$ and $2.8 \%$ of a country's total health care expenditure [19]. In another review of data from ten Western European countries, estimated obesity costs were found to be as high as $0.09 \%$ to $0.61 \%$ of Gross Domestic Product (GDP) [20]. Estimating the cost of obesity to society is critical for policy makers, public health planners, and other health stakeholders. Not only can the cost estimate be used to establish priorities for research and health resource use, but it can also be used to improve public awareness of the negative economic impacts of obesity. In the past, many attempts have been made to estimate the economic cost of obesity in western countries [21-24]; few studies of this kind were conducted in Asia. However, in light of the rapid and continuous increase in obesity prevalence, several countries in Asia including Korea [25], Taiwan [26], China [27], and Hong Kong [28] have begun to assess the economic cost of obesity.

In line with global trends, the prevalence of obesity in Thailand almost doubled between 1991 and 2009. According to the fourth National Health Examination Survey (NHES) 2008-9 [29], 28.4\% of adult Thai men and $40.1 \%$ of women were classified as obese (BMI $\geq$ $25 \mathrm{Kg} / \mathrm{M}^{2}$ ). More importantly, the NHES also found that obesity levels had risen disproportionately in rural areas [30], indicating that obesity was no longer only found in higher socioeconomic groups. Despite this rapid increase in obesity over the last ten years, no research has yet been conducted into the economic cost of obesity in Thailand. Our study aims to estimate the economic costs of obesity in Thailand, 2009.

\section{Methods}

This is a prevalence-based, cost-of-illness study. Costs included in the analyses were health care cost, cost of productivity loss due to premature mortality, and cost of productivity loss due to hospital-related absenteeism.

\section{Obesity and co-morbidities}

In this study, obesity is defined as having a BMI of $25 \mathrm{Kg} / \mathrm{m}^{2}$ or higher. To estimate the cost associated with obesity, a number of co-morbidities were identified and their respective costs calculated. Based on the degree of association with obesity, the availability of existing information and its importance in the Thai context, the following 12 co-morbidities were selected in our study: colon and colorectal cancer, breast cancer, endometrial cancer, hyperlipidemia, diabetes mellitus, depression, hypertension, ischemic heart disease, pulmonary embolism, stroke, gall bladder disease, and osteoarthritis. For each comorbidity, the Obesity Attributable Fraction (OAF), the proportion of the incidence of a co-morbidity in the population that is due to obesity, was calculated using the following formula [31]:

$$
O A F_{j}=\frac{\sum_{i=1}^{2} P_{i}\left(R R_{i j}-1\right)}{\sum_{i=0}^{2} P_{i}\left(R R_{i j}-1\right)+1}
$$

Where

$\mathrm{i}=$ Body Mass Index (BMI) level $(\mathrm{i}=1$ means $\mathrm{BMI} \geq$ 25.0-29.9 $\mathrm{kg} / \mathrm{m}^{2}$ and $\mathrm{i}=2$ means $\mathrm{BMI} \geq 30 \mathrm{~kg} / \mathrm{m}^{2}$ )

$\mathrm{j}=$ Co-morbidity related to obesity $(\mathrm{j}=1-12)$

$\mathrm{P}_{\mathrm{i}}=$ Prevalence of obesity at BMI level $\mathrm{i}$

$\mathrm{RR}_{\mathrm{ij}}=$ Relative Risk of co-morbidity $\mathrm{j}$ associated with obesity level i compared with the non-obese population

In this study, obesity prevalence $\left(\mathrm{P}_{\mathrm{i}}\right)$ was obtained from the 4th NHES [17] while the Relative Risks $\left(R_{\mathrm{ij}}\right)$ were derived from meta-analyses [32-34] as well as studies conducted in Asia [26,35].

\section{Health care cost}

The health care costs of obesity and the 12 co-morbidities were estimated for both inpatient and outpatient services. For each co-morbidity, the inpatient and outpatient healthcare costs attributable to obesity were calculated by multiplying the total number of patients with the given co-morbidity in Thailand by the corresponding OAF, and the average cost of each co-morbidity per person per year. Each co-morbidity total was then added together to give a total healthcare cost for obesity.

The outpatient data on the total number of patients and the data on the cost of outpatient visit(s) for each comorbidity per person per year in 2009 were obtained from the database of the Center for Health Equity Monitoring (CHEM), Faculty of Medicine, Naresuan University. This database includes outpatient information covered by the two major public health insurance schemes in Thailandthe Universal Coverage Scheme (UCS) and the Civil Medical Service Scheme (CSMBS) - from 675 out of 843 public hospitals (80\%) across all 76 provinces throughout the country. These two public health schemes cover approximately $80 \%$ of the total Thai population (approximately 67 million); the remaining $20 \%$ are covered by the Social Security Scheme (SSS), which is offered to formal private sector employees. To estimate the total number of outpatient visits in Thailand in 2009, it was assumed that $64 \%$ of total outpatient visits in Thailand would be those covered by the CHEM database.

The inpatient data on the total number of patients and the data on the cost of inpatient visit(s) for each comorbidity per person per year were obtained from the Central Office for Health care Information (COHI) 
database, 2009, which contains hospital admission data from all public hospitals for patients covered by the UCS and CSMBS (but not the SSS). It was assumed that the COHI data would represent $80 \%$ of total inpatients in Thailand.

\section{Cost of productivity loss due to premature mortality}

The costs associated with productivity loss due to premature mortality were calculated for each co-morbidity using the human capital approach. The number of deaths that could be attributed to obesity in 2009, disaggregated by age and gender, were multiplied by the average wage each person would receive if he or she lived through his or her lifespan. A discount rate of 3\% was employed [29]. The data on the total number of deaths from each co-morbidity were obtained from the 2004 Thai Burden of Disease (BOD) project, and data on average earnings were calculated from the 2009 National Economic and Social Survey.

Cost of productivity loss due to hospital related absenteeism The cost of hospital-related absenteeism was also calculated using the human capital approach. To estimate the cost of productivity loss due to hospital related absenteeism, the number of days that inpatients and outpatients with obesity-related conditions were absent from work in 2009 as a result of their obesity was multiplied by the average daily wage. Outpatient absentee data was obtained from the CHEM database; inpatient absentee data was obtained from the $\mathrm{COHI}$ database. The calculation was based on the assumption that the average outpatient visit took 0.5 days. The average daily wage was calculated by dividing Thailand's 2009 GDP per capita [36] by the number of working days in the same year.

\section{Results}

The overall relative risk estimates and OAFs for obesity and the 12 co-morbidities, disaggregated by gender, are presented in Table 1. OAF estimates indicate that about $24 \%$ to $52 \%$ of all cases of diabetes mellitus, $25 \%$ to $33 \%$ of all cases of ischemic heart disease, and $15 \%$ to $23 \%$ of all cases of osteoarthritis in Thailand are attributable to obesity, respectively.

Estimates of the overall economic costs of obesity, disaggregated by types of cost, gender, and co-morbidity are displayed in Table 2 . With regard to total cost, the three conditions that are found to incur the highest costs are diabetes mellitus (6,385.7 million baht), ischemic heart disease (2,168.4 million baht), and stroke (2,017.6 million baht).

As shown in Table 2, the estimated health care cost attributable to obesity is 5,584 million baht. Obesity-related health care costs for women are about 2.5 times higher than for men (4,015 million baht VS 1,569 million baht). The three conditions that incur the highest health care costs are diabetes mellitus (3,386.6 million baht), ischemic heart disease (1,070.6 million baht), and colorectal cancer (377.3 million baht).

The estimated cost of premature mortality as a result of obesity-related conditions is 5,864 million baht. The premature mortality costs incurred by men are 1.5 times higher than they are in women (3,531 million baht VS 2,333 million baht). The three conditions that incur the highest premature mortality costs are diabetes mellitus (2,550.2 million baht), stroke (1,800.6 million baht), and ischemic heart disease (1,034.9 million baht).

The estimated cost of productivity loss due to absenteeism as a result of obesity-related conditions is 694 million baht. Of this total, 448.8 million baht results from diabetes mellitus, 102.3 million baht from hypertension, and 62.8 million baht from ischemic heart disease.

A summary of all of the estimated costs attributable to obesity is presented in Table 3. The total estimated economic cost of obesity in Thailand is 12,142.1 million baht (725.3 million US\$PPP, 16.74 baht $=1$ US\$PPP [36] or $0.13 \%$ of GDP [36]. Health care costs account for $46 \%$ of the total cost or about $1.5 \%$ of the national health care expenditure [37], while productivity loss costs account for $56 \%$ of the total cost.

\section{Discussion}

Many studies have shown that obesity exerts a significant cost burden on a country's health system and productivity $[19,20]$. This was also found in this first analysis of obesity cost in the Thai context, where obesity-attributable costs were found to be substantial, accounting for $0.13 \%$ of GDP or $1.5 \%$ of the total national health expenditure. In addition, the analysis revealed that costs associated with heath care provision and costs associated with productivity loss were broadly similar, which are in line with the findings of previous studies [22,38,39]. The cost identified in this paper should be regarded as a minimum estimate since other related costs such as the cost of absenteeism not related to hospitalization, cost of presenteeism, and unemployment costs were not included in the analysis. Furthermore, due to the unavailability of data in Thailand, the cost of premature mortality due to obesity and the following five co-morbidities-gall bladder disease, obesity, hyperlipidemia, pulmonary embolism, and depressionwere not included in the analysis.

A WHO report [18] found that, globally, obesity and overweight account for $23 \%$ of coronary heart disease cases, $7-14 \%$ of cancer cases, and $44 \%$ of diabetes mellitus cases. These general proportions were also found in our analysis, which suggested that about $25-33 \%$ of ischemic heart cases, $2 \%$ of breast cancer cases, $17 \%$ of endometrial cancer cases, $8-9 \%$ of colon cancer cases, and $24-52 \%$ of diabetes mellitus cases in Thailand were associated with obesity. Unlike in Western countries [21-23], our study 
Table 1 Relative risks for selected co-morbidities in obese subjects and Obesity Attributable Fraction (OAF)

\begin{tabular}{|c|c|c|c|c|c|c|}
\hline \multirow[t]{3}{*}{ Diseases/conditions } & \multicolumn{4}{|c|}{ Relative risk of developing diseases } & \multicolumn{2}{|c|}{ Obesity attributable fraction (OAF) (\%) } \\
\hline & \multicolumn{2}{|c|}{ Male } & \multicolumn{2}{|c|}{ Female } & \multirow[t]{2}{*}{ Male } & \multirow[t]{2}{*}{ Female } \\
\hline & $1 *$ & $2^{* *}$ & $1 *$ & $2 * *$ & & \\
\hline Breast cancer [32] & - & - & 1.08 & 1.13 & - & 2 \\
\hline Colon and colorectal cancer [32] & 1.51 & 1.95 & 1.45 & 1.66 & 8 & 9 \\
\hline Depression [32] & 1.30 & 1.31 & 0.98 & 1.67 & 4 & 3 \\
\hline Diabetes mellitus [32] & 2.40 & 6.47 & 3.92 & 12.41 & 24 & 52 \\
\hline Endometrial cancer [32] & - & - & 1.53 & 3.22 & - & 17 \\
\hline Gall bladder [32] & 1.09 & 1.43 & 1.44 & 2.32 & 2 & 12 \\
\hline Hyperlipidemia [26] & 1.95 & 1.76 & 1.95 & 1.76 & 11 & 15 \\
\hline Hypertension [32] & 1.28 & 1.84 & 1.65 & 2.42 & 5 & 15 \\
\hline Ischemic heart disease [35] & 3.02 & 4.37 & 3.02 & 4.37 & 25 & 33 \\
\hline Obesity & 1.00 & 1.00 & 1.00 & 1.00 & 100 & 100 \\
\hline Osteoarthritis [32] & 2.76 & 4.20 & 1.80 & 1.96 & 23 & 15 \\
\hline Pulmonary embolism [32] & 1.91 & 3.51 & 1.91 & 3.51 & 15 & 22 \\
\hline Stroke [32] & 1.23 & 1.51 & 1.15 & 1.49 & 4 & 5 \\
\hline
\end{tabular}

${ }^{*} 1=\mathrm{BMI} 25.0-29.9 \mathrm{~kg} / \mathrm{m}^{2} *{ }^{2} 2=\mathrm{BMI} \geq 30 \mathrm{~kg} / \mathrm{m}^{2}$.

did not find cardiovascular disease related to obesity to be the primary leading cause of economic burden. In line with a previous study in Asia [25], and giving weight to recent concerns that have been voiced regarding the epidemic of obesity and type 2 diabetes in Asia [16], we found diabetes mellitus to be the first leading cause of obesity cost (6,385.7 million baht), followed by ischemic heart disease (2,168.4 million baht), and stroke (2017.6 million baht). Nevertheless, previous studies indicate
$[40,41]$ that reducing weight by $5-10 \%$ can improve blood sugar control and help reduce the risk of developing cardiovascular disease. Given the rise of obesity in Asia, and the prevalence of related conditions-particularly diabetes mellitus and cardiovascular disease [16]-interventions aimed at obesity control clearly deserve more attention.

In line with findings from previous studies in the US $[6,42,43]$, which found that obesity had a health impact equal or exceeding that of smoking and drinking, our

Table 2 Estimates of the economic costs of obesity in Thailand 2009 by types of costs, gender, and co-morbidity

\begin{tabular}{|c|c|c|c|c|c|c|c|c|c|}
\hline \multirow[t]{2}{*}{ Disease } & \multicolumn{2}{|c|}{$\begin{array}{l}\text { Health care cost } \\
\text { (Million baht) }\end{array}$} & \multicolumn{2}{|c|}{$\begin{array}{l}\text { Cost of premature } \\
\text { mortality (Million baht) }\end{array}$} & \multicolumn{2}{|c|}{$\begin{array}{l}\text { Cost of productivity loss due to } \\
\text { hospital-related absenteeism (Million baht) }\end{array}$} & \multicolumn{3}{|c|}{$\begin{array}{c}\text { Total cost } \\
\text { (Million baht) }\end{array}$} \\
\hline & Male & $\overline{\text { Female }}$ & Male & Female & Male & Female & Male & Female & All \\
\hline Diabetes mellitus & 663.8 & $2,722.8$ & $1,302.6$ & $1,247.6$ & 88.1 & 360.7 & $2,054.5$ & $4,331.2$ & $6,385.7$ \\
\hline Ischemic heart disease & 521.5 & 549.1 & 761.6 & 273.3 & 29.6 & 33.2 & $1,312.7$ & 855.7 & $2,168.4$ \\
\hline Stroke & 98.9 & 99.6 & $1,236.1$ & 564.5 & 9.2 & 9.4 & $1,344.1$ & 673.5 & $2,017.6$ \\
\hline Colon and rectal cancer & 188.0 & 189.3 & 203.5 & 119.0 & 6.0 & 6.3 & 397.4 & 314.7 & 712.1 \\
\hline Hypertension & 31.4 & 146.4 & 26.5 & 26.1 & 18.6 & 83.7 & 76.5 & 256.2 & 332.7 \\
\hline Osteoarthritis & 46.3 & 113.6 & 0.7 & 0.6 & 8.2 & 17.6 & 55.2 & 131.8 & 187 \\
\hline Gall bladder & 11.5 & 101.0 & - & - & 1.1 & 8.9 & 12.6 & 109.9 & 122.5 \\
\hline Endometrial cancer & - & 42.3 & - & 2.8 & - & 2.5 & 0 & 47.6 & 47.6 \\
\hline Breast cancer & - & 36.6 & - & 99.3 & - & 1.7 & 0 & 137.6 & 137.6 \\
\hline Obesity & 3.8 & 4.6 & - & - & 1.2 & 2.5 & 5.0 & 7.1 & 12.1 \\
\hline Hyperlipidemia & 0.9 & 2.1 & - & - & 1.1 & 2.5 & 2.0 & 4.6 & 6.6 \\
\hline Pulmonary embolism & 1.8 & 5.9 & - & - & 0.1 & 0.5 & 1.9 & 6.5 & 8.4 \\
\hline Depression & 0.8 & 1.8 & - & - & 0.4 & 0.7 & 1.3 & 2.5 & 3.8 \\
\hline Total & $1,568.7$ & $4,015.1$ & $3,531.0$ & $2,333.2$ & 163.6 & 530.2 & $5,263.2$ & $6,878.9$ & $12,142.1$ \\
\hline
\end{tabular}




\begin{tabular}{|c|c|c|}
\hline Cost & Million baht & $\%$ \\
\hline Direct cost (health care cost) & 5,584 & 46 \\
\hline OPD & 850 & \\
\hline IPD & 4,734 & \\
\hline Indirect cost (productivity loss) & 6,558 & 54 \\
\hline Premature mortality & 5,864 & \\
\hline Hospital-related absenteeism & 694 & \\
\hline Total cost & 12,142 & 100 \\
\hline$\%$ of total cost in term of GDP & 0.13 & \\
\hline $\begin{array}{l}\% \text { of Health care cost in term } \\
\text { of National health care expenditure [37] }\end{array}$ & 1.5 & \\
\hline
\end{tabular}

results indicate that health care costs attributable to obesity are the same as those attributable to alcohol consumption, which was estimated at 5,491 million baht in 2006 [44]. Despite this, the numbers of public health campaigns targeting obesity are fewer than those related to smoking and drinking. One explanation may be that obesity and the condition of being overweight are perceived as personal issues rather than social problems. However, our findings clearly show that the effect of obesity on the country's economy is significant, especially in terms of health care costs, which are currently shouldered by all tax payers in Thailand. It is clear that, to effectively tackle obesity in Thailand, a public health campaign targeting obesity epidemic should place emphasis on the impact of obesity on society as well as social responsibility without stigmatising those who are obese.

In this study, BMI was used as a measure to determine the prevalence of obesity. According to the WHO [45], a BMI reading of $25-29.9 \mathrm{~kg} / \mathrm{m}^{2}$ is indicative of an overweight condition, while a reading of $30 \mathrm{~kg} / \mathrm{m}^{2}$ or higher indicates obesity. However, in Asia, the risk of type 2 diabetes mellitus and cardiovascular disease is already high in those whose BMI is below $25 \mathrm{~kg} / \mathrm{m}^{2}$. In addition, at the same BMI, Asian populations are found to have higher levels of body fat than Western populations $[46,47]$. Therefore, it has been proposed that lower BMI readings should be used to identify those who are overweight or obese in the Asian population. A 2004 WHO expert consultation proposed that an appropriate cut off to measure the condition of being overweight and obese in Asian populations would be $23-24.9 \mathrm{~kg} / \mathrm{m}^{2}$ and $25 \mathrm{~kg} / \mathrm{m}^{2}$, respectively [47]. To permit comparison across previous studies in estimating the economic cost of obesity, a BMI reading of at least $25 \mathrm{~kg} / \mathrm{m}^{2}$ was used to define obesity in our study. Nevertheless, it should be noted that the estimate impact of obesity will be lower if a BMI reading of $30 \mathrm{~kg} / \mathrm{m}^{2}$ is used to define obesity.
In this study, the prevalence of obesity in 2009 was used to calculate the OAF. The estimated prevalence constitutes people with a varied time period of obesity. As induction times for chronic diseases may differ across persons and diseases and are not exactly known, we might have overestimated the cost from the impact of obesity as the lapse time need for developing comorbidity as well as duration of obesity were not taken into account. Nevertheless, these figures do inform at what cost the societal inevitably need to shoulder in the future without effective interventions to mitigate the current burden of obesity. In addition, the identification of induction times for chronic diseases is a priority area for future research related to obesity.

Another limitation that warrants further discussion is the reliance on estimated costs. While we acknowledge that the validity of our findings relies on the accuracy of a number of estimated parameters and assumptions, we are confident that the estimates are reasonably accurate. For instance, the CHEM and COHI databases (which were used to estimate health care costs) are the largest hospital databases available in Thailand. Nevertheless, we assumed that the COHI accounted for $80 \%$ of all inpatients in the country. However, based on the recent figures [48], patients in $\mathrm{COHI}$ database may account for $83 \%$ of the total population. Therefore, our results might slightly overestimate the impact of obesity. In addition, while these databases only include data from patients who are covered by the UCS and CSMBS schemes, we assume that obesity prevalence among beneficiaries of these two schemes will be comparable to those of the SSS. We acknowledge, however that this assumption may be somewhat limited as the SSS scheme covers those who are healthy enough to be employed in the private sector; this may mean that they suffer from lower levels of obesity. If this is the case, then the total cost of obesity would be somewhat lower than what we have estimated in this study. Lastly, since there was no Thai-specific relative risk data available, the relative risk data were obtained from meta-analysis review of global literature, including a number of Asian studies [26,32-35]. Future research on relative risk in Thailand, particularly for diabetes and cardiovascular disease, would be beneficial.

\section{Conclusions}

This study confirmed that obesity imposes a substantial economic burden on Thai society. In terms of health care cost, it is equivalent to that imposed by alcohol consumption. In light of the rapid and continuous increase in obesity prevalence in Thailand, large-scale comprehensive interventions for the prevention and control of obesity should be regarded as of public health priority in Thailand. 


\section{Competing interests}

The authors declare that they have no competing interests.

\section{Authors' contributions}

PP participated in study design, data collection, data analysis, and drafted the manuscript. NS participated in its design and coordination, data collection, and data analysis. RB participated in its design and data analysis. JY participated in its design and data collection. WA participated in its design, data collection and data analysis. YT conceived of the study, participated in its design and data analysis, MT conceived of the study, participated in its design and coordination, data collection, data analysis, and helped to draft the manuscript. All authors read and approved the final manuscript.

\section{Acknowledgements}

The Health Intervention and Technology Assessment Program is funded by the Thailand Research Fund under the Senior Research Scholar on Health Technology Assessment (RTA5580010), the Thai Health Promotion Foundation, the National Health Security Office, the Health Systems Research Institute, and the Bureau of Health Policy and Strategy, Ministry of Public Health. We are grateful for the support from the National Statistics Office, Central Office for Healthcare Information, the Center for Health Equity Monitoring, the Burden of Disease Project, and all members of the expert committee in providing us data and comments throughout the study.

\section{Author details}

${ }^{1}$ Social and Administrative Pharmacy Division, Department of Pharmacy, Faculty of Pharmacy, Mahidol University, Bangkok, Thailand. ${ }^{2}$ Health Intervention and Technology Assessment Program (HITAP), Ministry of Public Health, Nonthaburi, Thailand. ${ }^{3}$ Faculty of Medicine, Ramathibodi Hospital, Mahidol University, Bangkok, Thailand. ${ }^{4}$ Clinical Pharmacy Division, Department of Pharmacy, Faculty of Pharmacy, Mahidol University, Bangkok, Thailand.

Received: 20 August 2013 Accepted: 24 March 2014 Published: 2 April 2014

\section{References}

1. Obesity and overweight. [http://www.who.int/mediacentre/factsheets/ fs311/en/] Accessed: March 2013.

2. Burton BT, Foster WR, Hirsch J, Vanlttallie TB: Health implication of obesity: $\mathrm{NIH}$ consensus development conference. Int J Obes Relat Metab Disord 1985, 9:155-169.

3. Janssen I, Katzmarzyk PT, Ross R: Body mass index, waist circumference, and health risk: evidence in support of current National Institutes of Health guidelines. Arch Intern Med 2002, 162:2074-2079.

4. Must A, Spadano J, Coakley EH, Fileld AE, CoLditz G, Dietz WH: The disease burden associated with overweight and obesity. JAMA 1999, 282:1523-1529.

5. Pi-Sunyer FX: Medical hazards of obesity. Ann Intern Med 1993, 119:655-660.

6. Jia H, Lubetkin El: Trends in quality-adjusted life-years lost contributed by smoking and obesity. Am J Prev Med 2010, 38:138-144.

7. Jia H, Lubetkin El: Obesity-related quality-adjusted life years lost in the U.S. from 1993 to 2008. Am J Prev Med 2010, 39:220-227.

8. Mokdad AH, Marks JH, Stroup DF, Gerberding JL: Actual causes of death in the United States, 2000. J Am Med Assoc 2004, 291:1238-1245.

9. Gates DM, Succop P, Brehm BJ, Gillespie GL, Sommers BD: Obesity and presenteeism: the impact of body mass index on workplace productivity. J Occup Environ Med 2008, 50:39-45.

10. Jia H, Lubetkin El: The impact of obesity on health-related quality-of life in the general adult US population. J Public Health 2005, 27:156-164.

11. Larsson U, Karlsson J, Sullivan M: Impact of overwieght and obesity on health-related quality of life- a Swedish population study. Int J Obes Relat Metab Disord 2002, 26:417-424.

12. Sach TH, Barton GR, Doherty M, Muir KR, Jenkinson C, Avery AJ: The relationship between body mass index and health-related quality of life: comparing the EQ-5D, EuroQol VAS and SF-6D. Int J Obes (Lond) 2007, 31:189-196.

13. Wee HL, Wu Y, Thumboo J, Lee J, Tai ES: Assocation of body mass index with Short-Form 36 physical and mental component summary scores in a multiethinic Asian population. Int J Obes (Lond) 2010, 34:1034-1043.

14. Asia Pacific Cohort Studies Collaboration: The burden of overweight and obesity in the Asia-Pacific region. Obes Rev 2007, 8:191-196.
15. Ramachandran A, Snehalatha C: Rising burden of obesity in Asia. J Obesity 2010, 2010:1-8.

16. Yoon KH, Lee JH, Kim JW, Cho JH, Choi YH, Ko SH, Zimmet P, Son HY: Epidemic obestiy and type 2 diabetes in Asia. Lancet 2006, 368:1681-1688.

17. Misra A, Khurana L: Obesity and the metabolic syndrome in developing countries. J Clin Endocrinol Metab 2008, 93(Suppl 1):9-30.

18. World Health Organization: Obesity and Overweight. Geneva: World Health Organization; 2011

19. Withrow D, Alter DA: The economic burden of obesity worldwide: a systematic review of the direct costs of obesity. Obesity Rev 2011, 12:131-141.

20. Müller-Riemenschneider F, Reinhold T, Berghöfer A, Willich SN: HealthEconomic burden of obesity in Europe. Eur J Epidemiol 2008, 23:499-509.

21. Birmingham CL, Muller JL, Palepu A, Spinelli JJ, Anis AH: The cost of obesity in Canada. CMAJ 1999, 160:483-488.

22. Sander B, Bergemann R: Economic burden of obesity and its complications in Germany. Eur J Health Econ 2003, 4:248-253.

23. Swinburn B, Ashton T, Gillespie J, Cox B, Menon A, Simmons D, Birkbeck J: Health care costs of obesity in New Zealand. Int J Obes Relat Metab Disord 1997, 21:891-896.

24. Wolf AN, Colditz G: Social and economic effects of body weight in the United States. Am J Clin Nutr 1996, 63(Suppl 3):466-469.

25. Kang JH, Jeong BG, Cho YG, Song HR, Kim KA: Socioeconomic costs of overweight and obesity in Korean adults. J Korean Med Sci 2011, 26:1533-1540.

26. Fu T, Wen T, Yeh P, Chang C: Costs of metabolic syndrome-related diseases induced by obesity in Taiwan. Obesity Rev 2008, 9(Suppl 1):68-73.

27. Zhao W, Zhai Y, Hu J, Wang J, Yang Z, Kong L, Chen C: Economic burden of obesity-related chronic diseases in Mainland China. Obes Rev 2008, 9(Suppl 1):62-67.

28. Ko GTC: The cost of obesity in Hong Kong. Obes Rev 2008, 9(Suppl 1):74-77.

29. Permsuwan U, Guntawongwan K, Buddhawongsa P: Handling time in economic evaluation studies. J Med Assoc Thai 2008, 91(Suppl 2):53-58.

30. Aekplakorn W, Mo-Suwan L: Prevalence of obesity in Thailand. Obes Rev 2009, 10:589-592.

31. Walter SD: Estimation and interpretation of attributable risk in health research. Biometrics 1976, 32:829-849.

32. Guh DP, Zhang W, Bansback N, Amarsi Z, Birmingham CL, Anis AH: The incidence of co-morbidities related to obesity and overweight: a systematic review and meta-analysis. BMC Public Health 2009, 9(88):1-20.

33. Luppino FS, de Wit LM, Bouvy PF, Stijnen T, Cuijpers P, Penninx BW, Zitman FG: Overweight, obesity, and depression: a systematic review and meta-analysis of longitudinal studies. Arch Gen Psychiatry 2010, 67:220-229.

34. Prospective Studies Collaboration, Whitlock G, Lewington S, Sherliker P Clarke R, Emberson J, Halsey J, Qizilbash N, Collins R, Peto R: Body-mass index and cause-specific mortality in 900000 adults: collaborative analyses of 57 prospective studies. Lancet 2009, 373:1083-1096.

35. Jee SH, Sull JW, Park J, Lee SY, Ohrr H, Guallar E, Samet JM: Body-mass index and mortality in Korean men and women. N Engl J Med 2006, 355:779-787.

36. World Economic Outlook Database: September 2011. [http://www.who.int/ mediacentre/factsheets/fs311/en/] Accessed: March 2013.

37. The 2009-2010 NHA working group: National Health Accounts of Thailand 2009-2010. Nonthaburi, Thailand: International Health Policy Program, Ministry of Public Health; 2012.

38. Ahn B, Hyojee J: Socioeconomic cost of obesity in Korea. Korean Nutrition Soc 2005, 38:786-792.

39. Wolf AN, Colditz GA: Current estimates of the economic costs of obesity in the United States. Obes Res 1998, 6:97-106.

40. Bosello O, Armellini F, Zamboni M, Fitchet M: The benefits of modest weight loss in type II diabetes. Int J Obes Relat Metab Disord 1997, 21(Suppl 1):10-13.

41. Van Gaal LF, Wauters MA, De Leeuw $\mathbb{H}$ : The beneficial effects of modest weight loss on cardiovascular risk factors. Int J Obes Relat Metab Disord 1997, 21 (Suppl 1):5-9.

42. Sturm R: The effects of obesity, smoking, and drinking on medical problems and costs. Health Affairs 2002, 21:245-253.

43. Sturm R, Wells KB: Does obesity contribute as much to mortality as poverty or smoking? Publ Hlth 2001, 115:229-235.

44. Thavorncharoensap M, Teerawattananon Y, Yothasamut J, Lertpitakpong C, Thitiboonsuwan K, Neramitpitagkul P, Chaikledkaew U: The economic costs of alcohol consumption in Thailand, 2006. BMC Public Health 2010, 10:323.

45. WHO Expert Committee: Physical Status: the Use and Interpretation of Anthropometry. Geneva; 1995 
46. Durenberg $P$, Yap M, van Staveren WA: Body mass index and percent body fat: a meta-analysis among different ethnic groups. Int $J$ Obesity 1998, 22:1164-1171.

47. WHO Expert consultation: Appropriate body-mass index for Asian populations and its implications for policy and intervention strategies. Lancet 2004, 363:157-163.

48. Thammatach-aree J: Health Systems, Public Health Programs, and Social Determinants of Health: Thailand. Rio de Janeiro, Brazil: Proceeding of the World Health Organization for the World Conference on Social Determinants of Health; 2011.

doi:10.1186/1472-6963-14-146

Cite this article as: Pitayatienanan et al:: Economic costs of obesity in Thailand: a retrospective cost-of-illness study. BMC Health Services Research 2014 14:146.

\section{Submit your next manuscript to BioMed Central and take full advantage of:}

- Convenient online submission

- Thorough peer review

- No space constraints or color figure charges

- Immediate publication on acceptance

- Inclusion in PubMed, CAS, Scopus and Google Scholar

- Research which is freely available for redistribution 